\title{
Analysis of General Factors for Formation of Engineering and Scientific-and-Technological Staff
}

\author{
Vyacheslav Mikhaylovich Prikhodko \\ Moscow Automobile and Road Construction State Technical University (MADI), \\ Moscow, Russian Federation \\ Ekaterina Igorevna Makarenko \\ Sociology and Management Department, Moscow Automobile and Road Construction State Technical University (MADI), \\ Moscow, Russian Federation

\section{Aleksandr Vyacheslavovich Akhterov} \\ Sociology and Management Department, Moscow Automobile and Road Construction State Technical University (MADI), \\ Moscow, Russian Federation

\section{Olga Vladimirovna Lezina} \\ Sociology and Management Department, Moscow Automobile and Road Construction State Technical University (MADI), \\ Moscow, Russian Federation \\ Correspondence: Sociology and Management Department, \\ Moscow Automobile and Road Construction State Technical University (MADI), \\ Leningradskiy Prosp., 64, Moscow, Russian Federation, 125319
}

Doi:10.5901/mjss.2015.v6n3s3p123

\section{Abstract}

The paper is dedicated to analysis of general factors for formation of engineering and scientific-and-technological staff in the Russian Federation and also to modeling of one of them. In the work there are six objective factors: economic status of country and labour market state, scientific and technical policy, political and legal situation, globalization and international differentiation of labor, financial standing of population, and state of educational system. The analysis of dynamics of number of specialists of higher qualification level in area of natural and technical sciences witnesses increasing attraction of engineers to economy of the country and strengthening of their positions on labour market. In this connection the task of own production development and support of the branches, which are not belong to primary production, appear to be one of the most important for future economic development. Despite acute need of economy for engineering and technical workers, many of them, as researches show, feel socially unprotected. One of the main factors for formation of engineering and scientific-and-technological staff is the educational system, while one of the main stages is the training in graduate school. To model this process the present work uses the functional modeling methodology that is also known as Structured Analysis and Design Technique (SADT). As a result of SADT-modeling using four general processes of formation of engineering and scientific-and-technological staff were distinguished: (1) collaboration with branch research institutes; (2) specialized companies integration; (3) creation of interdepartmental complexes for realization of cross-disciplinary projects; (4) execution of cross-disciplinary projects and making of master's thesis. The goal of the first project is the formation of magistrand's competences linked to carrying-out of work scientific and research and developmental works. The goal of the second process is the formation of magistrand's competences linked to competences linked to manufacturing activity of corresponding branch. The third process is aimed at the formation of academic, regulatory and organizational provision and realization of cross-disciplinary projects. The goal of the last process is the execution of cross-disciplinary projects by magistrands and making of master's thesis at the end of training in graduate school.

Keywords: engineering and scientific-and-technological staff, technical intelligentsia, higher education, SADT-modeling.

\section{Introduction}

The engineering staff is the basis for successful economy of any industrially-developed country. Changes of economic conditions and social reality put before higher technical school a number of tasks on improvement of engineering 
education. Primarily - it is the training of engineering staff on brand new basis that would correspond to the requirements of labour market and requests of economical development.

In the Russian scientific tradition it is customary to identify the engineering staff as consisting of technical intelligentsia - the graduates of technical higher education institutions involved in the sphere of development of intellectual products in industries and high-technology sectors of economy (Makarenko E.I., 2013).

Section 2 of the present work is dedicated to analysis of objective factors for formation of engineering and scientific-and-technological staff. In sections 3 and 4 there is detailed description of SADT-modeling of the process of engineering and scientific-and-technological staff formation by the example of graduate school training.

\section{Method}

The SADT methodology and the IDEF0 standard based on it represent a complex of rules and procedures designed for building of functional model of object or process of chosen topical area. The functional model in IDEF0 is understood to be the set of diagrams connected with each other by interface arrows and aimed at attaining the goal of modeling. In such a way, any modeling process, in accordance with IDEF0 standard, starts with goal setting.

Decomposing is the process of sequential division of modeling object into smaller blocks and interface arrows that connect them.

The interface arrows on IDEF0 diagrams can be of four types: input arrows, output arrows, control arrows and arrows of mechanisms or resources (figure 1).

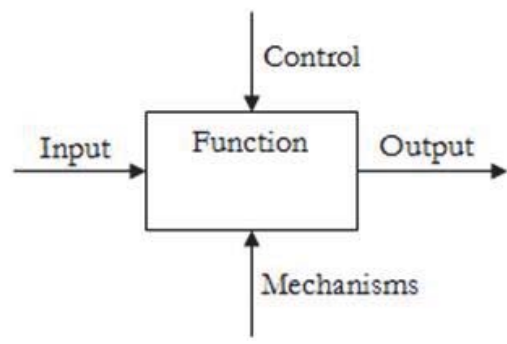

Figure 1. General diagram of interface arcs in SADT-modeling

The input arcs reflect the present, material or non-material, objects that are transformed by considered function into output. The input arcs enter the block of functions from the left and are not obligatory (IDEF0, 1993).

The output arcs reflect the present, material or non-material, objects that were produced by function. The output arcs come out of the block of functions from the right and are obligatory for any block (IDEF0, 1993).

The control arcs reflect the present, material or non-material, objects that regulate or create conditions for transformation of input objects into output ones. The control arcs enter the block of functions from above and are also obligatory (IDEF0, 1993).

The arcs of mechanisms or resources reflect the present, material or non-material, objects, with help of which input objects transform into output ones. The arcs of mechanisms enter the block of functions from below and can be absent in diagram, if from the point of view of modeling goal the resources for exercise of considered function are not important (IDEF0, 1993).

The diagram of higher level is called a context diagram. It is designated as $\mathrm{A}-0$, while a block of functions is designated as A0. The context diagram, as the term suggests, defines the context of modeled function, i.e. - the objects of environment being significant from the point of view of modeling goals. The decomposing of context diagram leads to building of diagram designated as $A 0$ and containing subfunctions. To preserve the entirety of modeling process it is necessary the arcs located in the parental diagram to be in the daughter one as well. The exception is for so-called tunnel arcs, which are denoted with two parentheses in the beginning or in the end of an arc. If an arc possesses the tunnel input, it means the arc is absent in parental diagram and appears only in the current diagram. If an arc possesses the tunnel output, the arc will be absent in daughter diagram.

Building of a model represents an iterated process of decomposing of considered function into subprocesses up to the level that is being necessary from the modeling goals' point of view. 


\section{Results}

\subsection{Main factors for formation of engineering and scientific-and-technological staff}

The present work is focused on objective factors of social development of modern technical intelligentsia. The objective factors having impact on the qualitative state of technical intelligentsia and its role in society cover:

- Economic status of country, labour market state.

- Scientific and technical policy.

- Political and legal situation.

- Globalization and international differentiation of labor.

- Financial standing of population.

- State of educational system.

\subsubsection{Economic status of country, labour market state}

The economic status of country is the most important and significant factor defining the qualitative state of engineering staff. Regretfully, we have to state that the economy of Russia is in the state of stagnation after social transformations and transition to market relations. This applies especially to material and technical production and real sector of economy. It is known that in real sector of economy there is reduction of profitability and the volume of output, and that implementation of new types of production is shifted into low gear. Unfortunately, in the economy of Russia the dependence of GDP refill from such raw-material sources as oil, gas and timber is clearly seen. The material and technical state of production and real sector of economy remain hard and there are no innovative breakthroughs. Members of staff of Institute of World Economy and International Relations (IMEMO) have made a disappointing conclusion: "The economical development of the country in 2014 was characterized with further growth rate reduction on the background of deterioration of conditions for trade and investment cooperation with main foreign partners and violent fluctuations of conjuncture on raw-material and exchange markets." (Dynkin and Baranovsky, 2014).

In these latter days the emphasis in economical development is put on such branches as defence industry complex, machine-tool and instrumentation making, power engineering industry, equipment for field and Arctic shelf development. With the correct approach and additional investments these branches can provide an impetus for other sectors and will promote both - the development of economy and formation of new generation of engineering staff.

The transition to market economy has influenced the emergence of labour market that can be defined as "free movement of workers choosing sphere for applying their skills in labour" (Vasiliev V.N. and Gurtov V.A., 2008). The structure of average annual number of persons engaged in economy by types of economic activity, according to the data of State Statistics Service, is shown in figure 2 (the State Statistics Service, 2014).

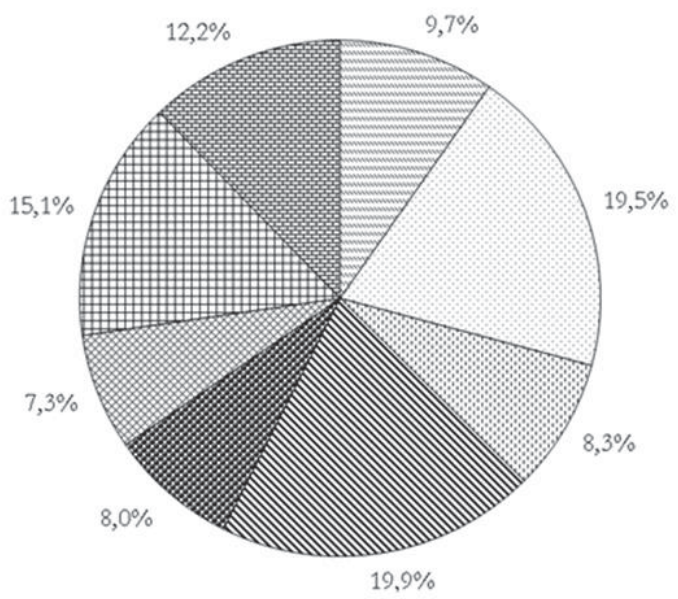

Figure 2. The structure of average annual number of persons engaged in economy by types of economic activity in 2012.

- $\quad 9,7 \%$ - Farming industry, hunting field and forestry; fishery and pisciculture. 
- $\quad 19,5 \%$ - Extraction of commercial minerals; processing production; production and distribution of electrical power, gas and water.

- $\quad 8,3 \%$ - Building and construction.

- 19,9\% - Wholesale and retail trade; repair of motor vehicle, motorcycles, household goods and personal demand items; hotels and restaurants.

- $\quad 8,0 \%$ - Transport and communications.

- $\quad 7,3 \%$ - State administration and provision of military security; social insurance; financial activity.

- $\quad 15,1 \%$ - Education, healthcare and delivery of social services.

- $12,2 \%$ - Other types of activity.

According to the data of selective survey on problems of population employment and particularly on primary employment, in 2013 there were 3538 specialists of higher qualification level in the area of natural and technical sciences. The representatives of technical intelligentsia take the leading positions in the employment structure, being in advance even of specialists from the sphere of education (2 635 thous. people), where the positions of highly educated staff were traditionally high. In addition, we should note that for the recent time in the employment structure there is an increase of engineering staff -3137 thous. people in 2012 (figure 3) (Federal State Statistics Service, 2014). Undoubtedly, this witnesses the increasing attraction of engineers to economy of the country and strengthening of their positions on labour market, what gives evidence of renewal of prestige of engineering professions.

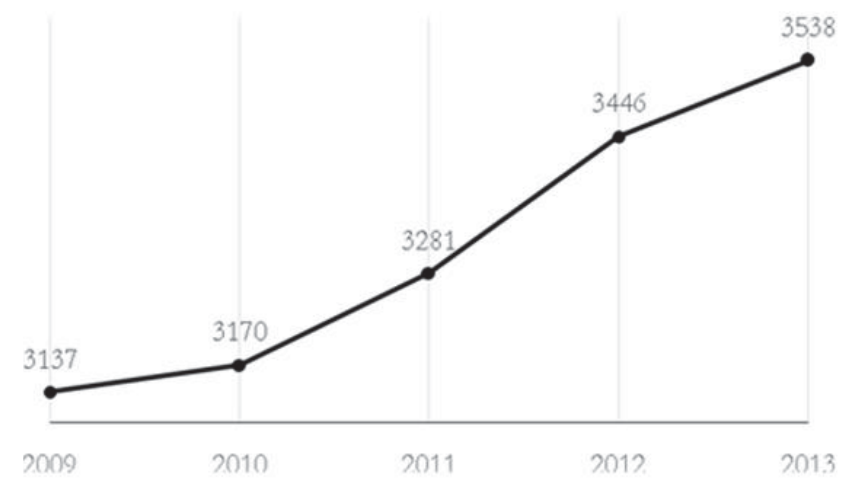

Figure 3. The dynamics of number of specialists of higher qualification level in area of natural and technical sciences

\subsubsection{Scientific and technical policy}

One of the main problems being typical for Russian economy is the state of its scientific and technological provision, promotion and implementation of national advanced technologies. Today in different governmental, social and scientific organizations there is technological inferiority of Russian economy, the leading branches become dependent upon western companies.

For the purpose of realization of scientific and technological development one should examine the experience of leading foreign companies, in which the achievements of fundamental and applied science find application in strategic promotion to the market of technologies. Thus, for example, academician Primakov E.M. considers that in this regard we can use the experience of the USA in creation of networks for innovations' promotion - when on the basis of American universities venture small companies are established. Our advantage is that in the Russian Federation there is Academy of Sciences with broad network of research institutes. The task here is maximum use of opportunities and the Academy, and higher education institutions for transition of Russia to new technological mode. In our country there are 110 centers of technologies' transfer, more than 100 technological parks, about 120 business incubators, i.e. - the basic infrastructural elements of modern networks for promotion of innovations to internal and foreign consumers. This network is also badly in need for improvement and governmental support (Primakov E.M., 2011). The matters of scientific provision of manufacturing activity have important significance for formation of qualitative component of modern engineering staff. 


\subsubsection{Political and legal situation}

The main criterion of analysis of impact of political and legal system on the state of engineering staff is the indicator of system's stability. This is quite important for creation of fruitful soil for economic regulation, social provision of population, attraction of foreign investments, and arrangement of suitable conditions for work. The adoption of Law "Of industrial policy in the Russian Federation" at the end of 2014 should positively influence the engineering staff and create legal basis for their activity (Rossiyskaya gazeta, January 12, 2015).

\subsubsection{Globalization and international differentiation of labor}

Studying of social and economical situation of Russia is impossible without due account of involvement of all the countries into global world economic management and international differentiation of labor. Globalization is understood to be the processes of formation of more or less consolidated worldwide systems in economy, technology, informational environment and in the sphere of culture. As a result of such processes countries and nations become not only interrelated between each other, but also interdependent. The author shares the position of corresponding member of Russian Academy of Sciences Rutkevich M.N., who notes that "globalization is being historically inevitable process. The question at issue is how and on whose behalf it performs" (Rutkevich M.N., 2004). That is why the task of states and, above all, of their governments is in the most effective way to connect all the advantages of globalization with national interests in area of economy, politics and culture.

In the most acute way the globalization makes itself evident in scientific and technical area. Underestimation of national opportunities and available resources here can lead to profound social consequences and at last - to the loss of not only technological, but also national sovereignty. In this connection the protection of interests of national technical staff and systematic work on its qualitative renewal turn out to be important component in positioning of a country in the international arena.

In number of UN documents globalization is characterized with emergence of:

- currencies markets and capitals on global level;

- new means of globalization (Internet, cellular telephones, satellite TV);

- new global rules and standards (international agreements concerning trade, services, intellectual property), which possess binding force for national governments;

- new global organizations (World Trade Organization, multinational corporations).

Here we should note that World Trade Organization (WTO) established in 1995 replaced General Agreement on Tariffs and Trade (GATT) as only international body dealing with global rules for trade between countries. It is no a specialized institution, however it possesses some mechanisms and the practice of cooperation with United Nations Organization. The mission of WTO is the provision of assistance in adjustment of trading process in the frameworks of the system based on definite rules, objective settlement of trading disputes between governments, organization of trade negotiations. At the heart of such activity there are 60 agreements of WTO - the general legal standards of international commerce and trade policy. The principles, on which these agreements are based, include absence of discrimination (the regime of most favoured nation and national treatment clause), more immediate conditions for trade, encouragement of competition and additional provisions for less developed countries. One of WTO goals is the struggle with protectionism.

Despite official accession of Russia to Marrakesh Agreement Establishing the WTO (the protocol of August 22, 2012), there are no single-value estimates about necessity and rightness of country's entry to WTO. The official position is the following: "It is obvious that there will be pros and cons in some sphere, but on the global level we will gain benefit in definite number of years even due to the fact that we will bring our institutions into compliance with analogous institutions of other countries. That is why we will be able to see the results not in the short term, but in five or ten years", said Prime Minister of the Russian Federation Medvedev D.A. on "Antikontrafact-2012" forum (Rossiyskaya gazeta, 2012). At the present time the entry of Russia to WTO is understood to be most advantageous for the branches using national mineral resources: oil, gas, timber, and ore. However, in specialists' opinion, the accession to WTO does not stimulate growth of domestic production, does not promote development of industry and farming industry, as it facilitates the access of foreign goods to internal market. For example, for national automobile manufacturing the significant risk owing to entry to WTO occurs - the abatement in fees for second hand car. In fact, the entry of Russia to WTO has led to social contradiction between acclaimed tasks of construction of non-resource economy and development of national production on the one hand and support of extractive industries, creation of regime for favour of export of oil, gas and 
other raw materials - on the other hand. It is known that at the end of 2014 and beginning of 2015 the situation on the world market of oil products had cardinally changed - oil started rapid fall in price. That is why the task of development of own production and support of non-resource branches appear to be one of the most important for future economical development.

\subsubsection{Financial standing of population}

Financial standing of population as a whole is the important factor that characterizes social position and living standard of engineering staff. The representatives of technical intelligentsia do not differ with high level of material safety net. The data is attested with "Modernization of economy and the technical intelligentsia" survey that was conducted in 2011 by "GALSI" and "MADI" research team. The sampling population made up 910 people, who were holding position of engineers and heads of departments of enterprises and organizations of various types of ownership located in Moscow and the Moscow, Kaluga, Nizhny Novgorod regions, in Tolyatti, etc.

The research of subjective factors, i.e. - the opinion of technical intelligentsia' representatives allows stating that the living standard of technical intelligentsia remains rather low, and many of them have to combine their main activity with additional one, i.e. - to turn an honest penny or just earn extra money. Respondents to a greater degree negatively evaluate the impact of market reforms on position of their family (38\%), their enterprise (35\%) and the country as a whole (41\%). Positive opinion on change of the social position was given by $31 \%, 24 \%, 17 \%$ of respondents correspondingly. The collapse of industry branches based on science and high technologies has appeared to be the main loss for today's engineers - it is considered the reason for decrease of living standard by almost a half of respondents $-43 \%$.

Another one indicative factor for bad social feeling of the present part of Russian society is the extremely low degree of satisfaction with salary - altogether $87 \%(!)$ of respondents have negative attitude towards remuneration of their labour. And only $12 \%$ of respondents feel themselves socially protected (including access to medical service, possibility of rest and other social benefits).

\subsubsection{State of educational system}

The state of educational system is the key factor of society development in whole. It is known that higher technical education has crucial impact on formation of engineering staff. Main tasks of engineering education development at the present stage cover:

1. Globalization of knowledge on basis of Internet.

2. Creation of international and national associations or "networks" uniting higher technical institutions between each other or including such manufacturing corporations and scientific organizations.

3. Public organizations are more often attracted to higher education's quality control.

4. Expansion of competency building approach.

5. Use of electronic and remote technologies in education.

6. Development of cross-disciplinary relations, modular approach to formation of educational standards.

7. Renewal of project method of training and other pragmatic methods in number of countries.

8. Elaboration of new professions' nomenclature and transition to level-based system for training of personnel with higher education.

The system of technical education is at the stage of difficult transition: from Soviet standards of education, which had been forming for decades and which were admitted as one of the best in the world and to a great degree corresponded to the needs of country's economical development, - to modern ones based on market relations. Upon the conditions of educational system transformation the task of fully-featured training of engineering and technical staff by means of graduate school as one of the most important levels of higher education moves to the forefront.

The Russian higher technical school possesses age old traditions and the authority in world educational space. In accordance with the Law "Of education in the Russian Federation", education in Russia has the structure shown in figure 4.

One of the main stages of engineering and scientific-and-technical staff formation is the graduate school. Namely the training in graduate school provides full integration of competences linked to scientific inquiry and conduction of developmental works and competences linked to specialized manufacturing activity into the future of a specialist. For detailed understanding of the processes of formation of engineering and scientific-and-technical staff the construction of functional model of considered processes is required. For this purpose it will be reasonable to use the methodology of functional modeling or - Structured Analysis and Design Technique (SADT). 


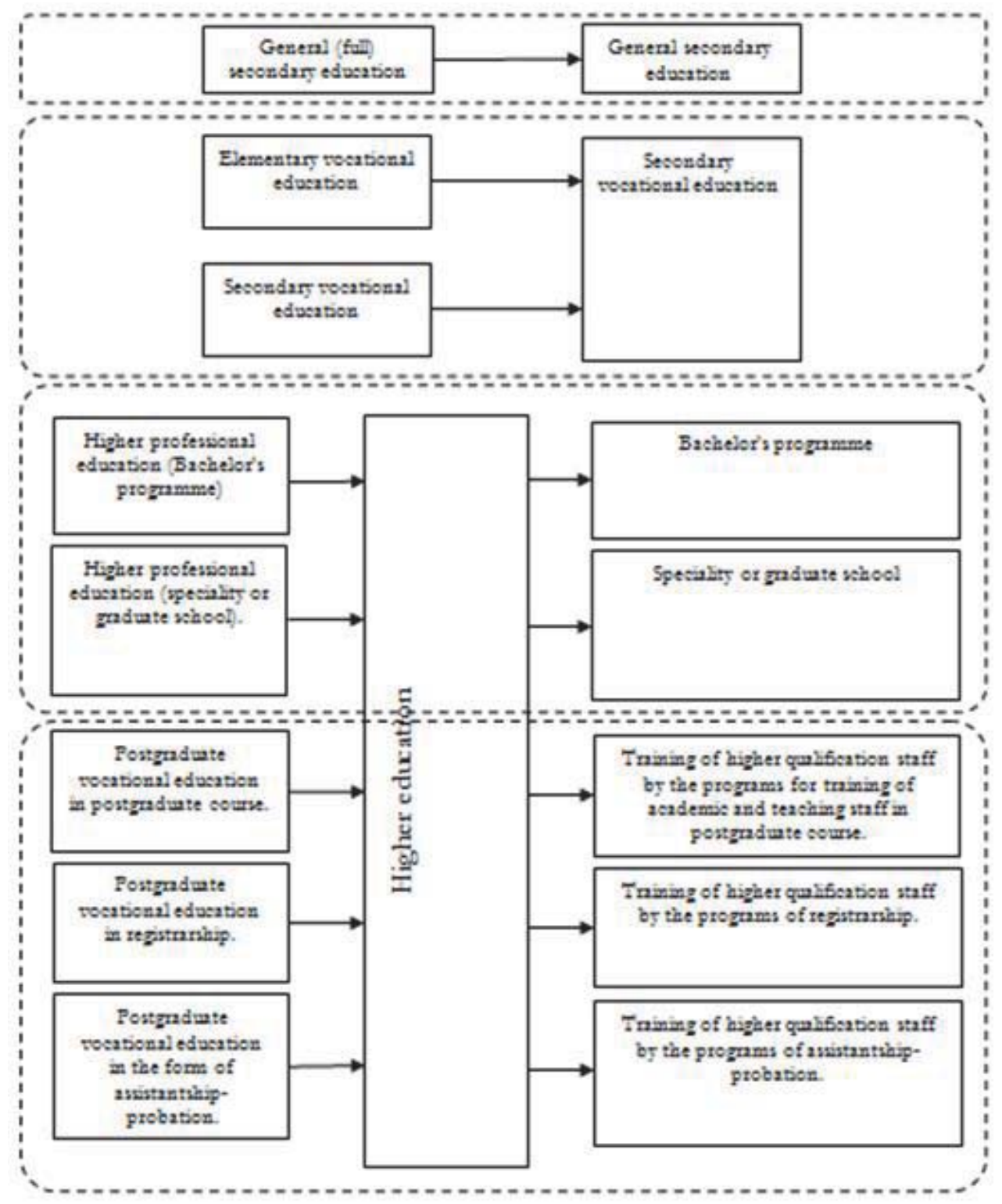

Figure 4. The structure of education in the Russian Federation

\subsection{SADT-modeling of the process of engineering and scientific-and-technical staff formation}

As it was mentioned above, the first step in the process of modeling of any process is the modeling's goals formulation. In the present work the goal is formulated in the following manner: to understand what functions should be included into the process of engineering and scientific-and-technical staff formation in the course of training in postgraduate school and how these functions interconnected between each other.

\subsubsection{A-0 context diagram for the process engineering and scientific-and-technical staff formation in the course of} training in postgraduate school

The context diagram for the process engineering and scientific-and-technical staff formation in the course of training in postgraduate school is shown in figure 5 . 


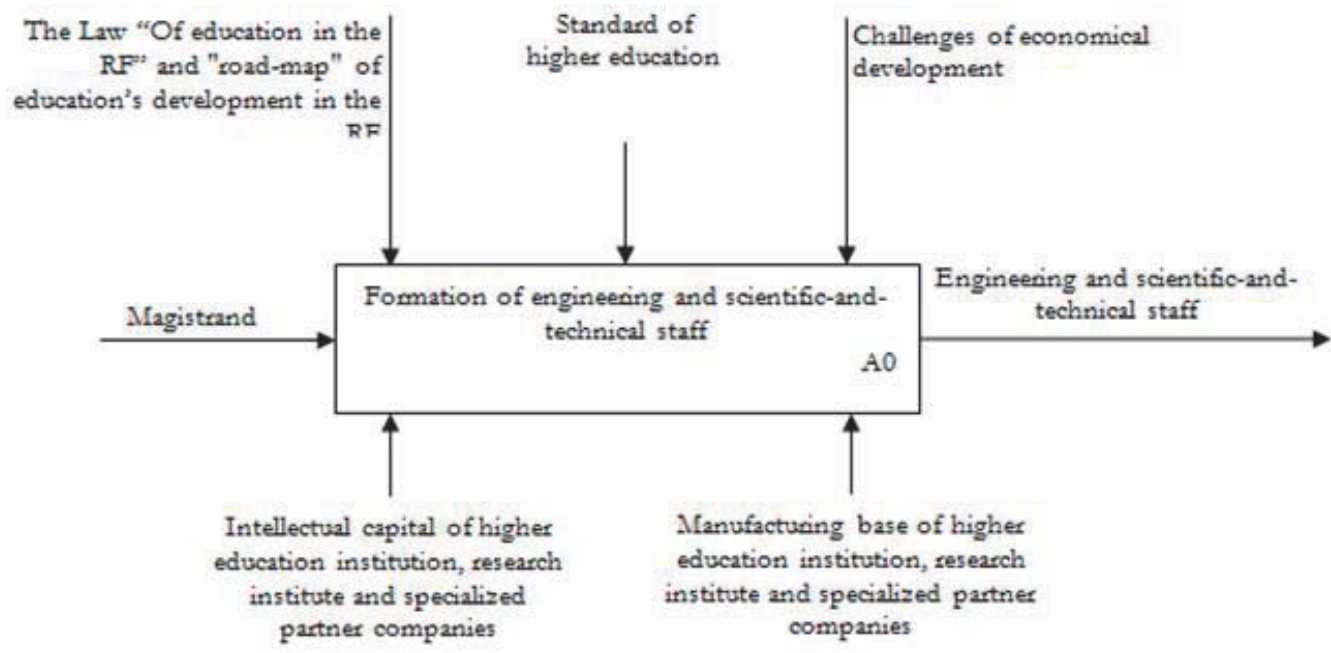

Figure 5. The A-0 context diagram for the process of formation of engineering and scientific-and-technical staff during training in graduate school.

In accordance with SADT rules the diagram is read in the following manner: the formation of engineering and scientificand-technical staff formation in the course of training in postgraduate school is primarily determined by the challenges of economical development of the country and requests of labour market. The postgraduate school pertains to higher education and is subject to two main documents having federal level (the Law "Of education in the RF" and "road-map" of education and science development in the RF) and also the standard of corresponding direction. The special emphasis should be put on the resources for realization of considered process. They include intellectual capital of higher education institution, research institutes and specialized partner companies, with which contractual arrangements are concluded, and also manufacturing bases taking part in the training of organizations' masters (higher education institution, partner research institutions and specialized companies).

The intellectual capital is the "aggregate of knowledge, information, experience, qualification and motivation of personnel, organizational opportunities, communication channel and technologies capable of creating added value and providing the competitive advantages of organization on market " (Gaponenko A.L. and Orlova T.M., 2008).

In (Stewart T.A., 1997) there is the following structure of intellectual capital: "Human capital - is the part of intellectual capital that has the direct relation to a man. It covers knowledge, practical skills, creative and cognitive powers of people, their ethical values, personal and leadership features, culture of labour, which are used by individual or organization for acquisition of income. Organizational capital - is the part of intellectual capital possessing relation to organization as a whole. It includes procedures, technologies, management systems, hardware and software, organizational forms and structures, patents, organization's culture. Consumer's capital - is the part of intellectual capital consisting of bonds and stable relations with clients and consumers" (Stewart T.A., 1997).

In the present work we consider the first two components of intellectual capital. Thus, to turn magistrands into professional engineers and scientific-and-research staff there is a need for human and organizational capitals of the higher education institution itself, as well as of research institute and specialized companies, with which the contractual arrangements are concluded.

\subsubsection{A0 diagram for the process of engineering and scientific-and-technical staff formation in the course of training in postgraduate school}

The specification of context diagram is shown in figure 6, where there are main subprocesses for engineering and scientific-and-technical staff formation in the course of training in postgraduate school: cooperation with branch research institutes, specialized companies integration, creation of interdepartmental complexes for realization of cross-disciplinary projects, execution of cross-disciplinary projects and making of master's thesis. 


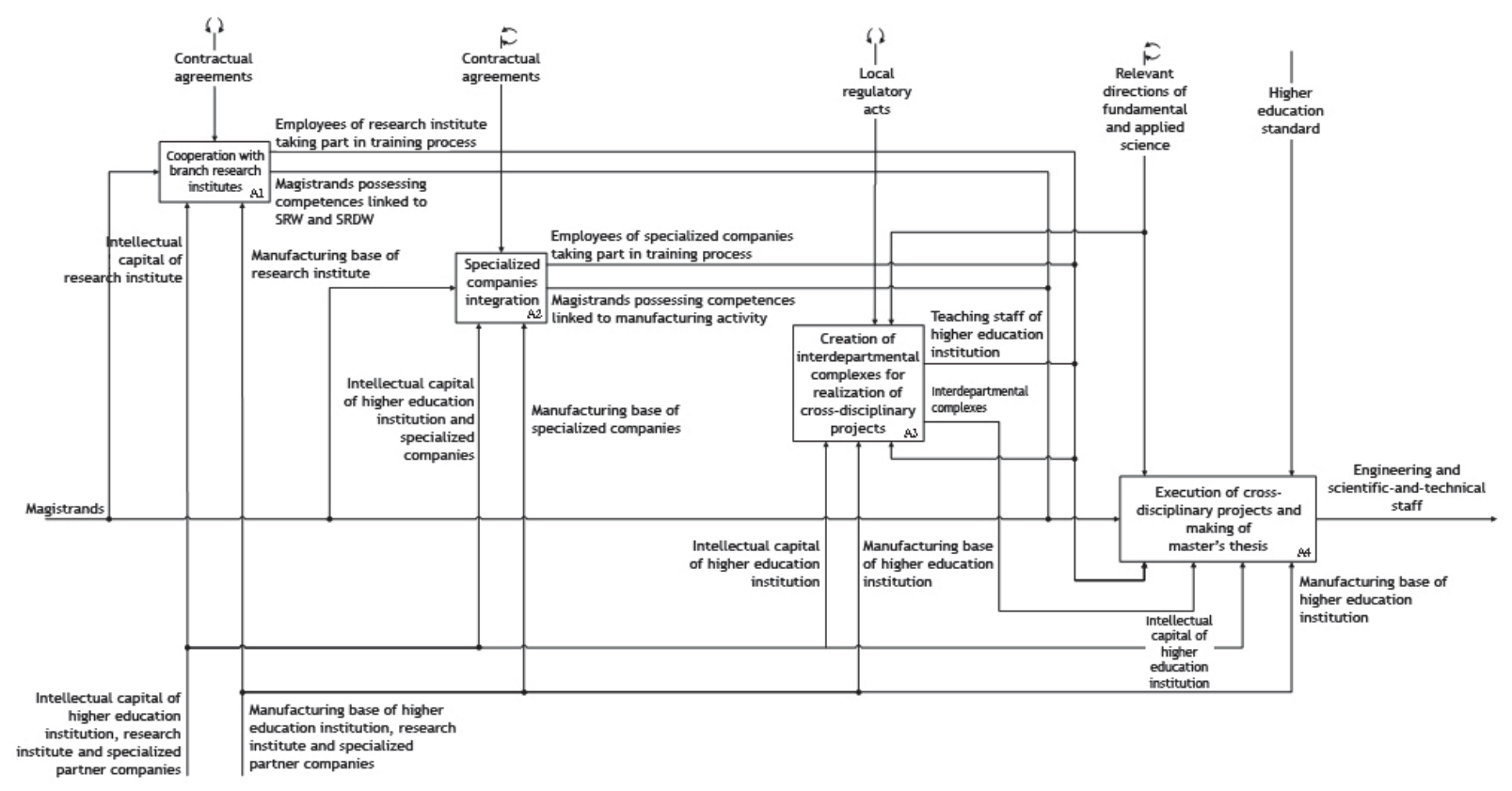

Figure 6. A0 diagram for the process of engineering and scientific-and-technical staff formation in the course of training in postgraduate school.

Block A1. Cooperation with branch research institutes. The aim of the process is the formation of magistrand's competences linked to execution of scientific-and-research works (SRW) and scientific-and-research and developmental works (SRDW). The input for this process is represented with magistrands, who in the process of execution of SRW and SRDW acquire the necessary competences. The output of the present process is represented with personnel of research institute taking part in masters' training. The resources for realization of the process are the intellectual capital of research institute (i.e. - two of his components: human organizational capitals) and its manufacturing base.

Block A2. Cooperation with specialized companies. On the analogy of cooperation with research institutes there is interaction with specialized companies, with which the association agreement was concluded. The output of this process is represented with magistrands possessing competences linked to manufacturing activity of corresponding area, and also personnel of specialized companies included into the process. The resources for the process are the intellectual potential of higher education institution and specialized partner company, plus, its manufacturing base.

Block A3. Creation of interdepartmental complexes for realization of cross-disciplinary projects. The present process is aimed at formation of academic, regulatory and organizational provision (interdepartmental complex) for realization of cross-disciplinary projects. The cross-disciplinary project is understood to be the goal-oriented time- and resources-limited activity performed by a magistrand with assistance of specially formed teaching staff (that can consist either of teacher of higher education institution, so of personnel of partner research institutes and specialized companies). The main feature of the present projects is their cross-disciplinary. This means that to perform the project the magistrand has to show knowledge not only of his topical area, but also of allied areas, to demonstrate the understanding of economy of the topical area and, probably, to show management skills. The creation of such type of interdepartmental complexes should be based on actual direction of fundamental and applied science, what is made evident by corresponding control arc. As an output we have developed interdepartmental complexes and staff composition of higher education institution, which will help magistrand when realizing project. The resources here are the intellectual capital of higher education institution, personnel of partner research institutes and specialized companies involved into teaching process, and also manufacturing base of higher education institution, as interdepartmental complexes are developed on higher education institution's base.

Block A4. Execution of cross-disciplinary projects and making of master's thesis. If the previous block (block A3) was aimed at creation of interdepartmental complexes for support of cross-disciplinary projects' realization (magistrands do not participate in the present process), the goal of this process is the execution of projects by magistrands and making of master's thesis at the end of training in postgraduate school. Only after realization of this process we can talk that our magistrands have acquired all the necessary competences and can be called technical intelligentsia. We should also pay 
attention to the fact that the input for this process is represented with both - the magistrands acquired the competences linked to scientific-and-research activity and branch manufacturing activity, and magistrands, who are in the beginning of their training in postgraduate school. The resources for the process are the personnel of partner research institutes and specialized companies involved into teaching process, earlier created interdepartmental complexes, intellectual capital of higher education institution and materiel and technical provision of training process. The control is represented with actual directions of fundamental and applied science and the standard of higher education that regulates the training content.

\subsubsection{A1 diagram for the process of engineering and scientific-and-technical staff formation in the course of training in postgraduate school. Process: "Cooperation with branch research institutes"}

Next we will consider the decomposing of four blocks of A0 diagram. In figure 7 there is A1 diagram that shows the content of A1 process.

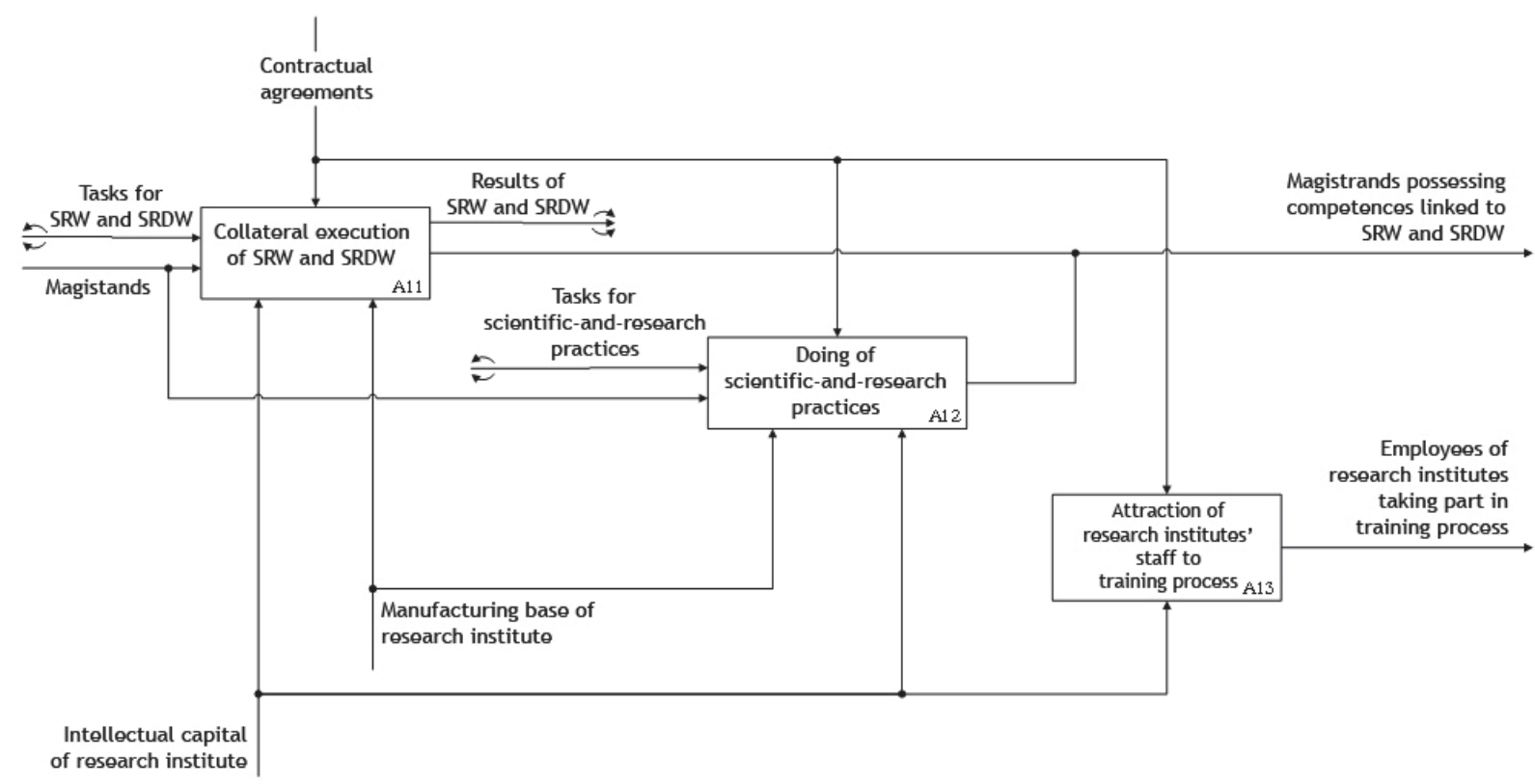

Figure 7. A1 diagram for the process of engineering and scientific-and-technical staff formation in the course of training in postgraduate school. Process: "Cooperation with branch research institutes"

Block A11. Collateral execution of SRW and SRDW. The aim of the present process is the attraction of magistrands to execution of SRW and SRDW in research institutes, with which the contractual arrangements are concluded (see the control arc). The input for the process is represented with magistrands and also the task for SRW and/or SRDW. The output, correspondingly, is the magistrands possessing competences linked to SRW and SRDW, and also the results of collateral execution of SRW and/or SRDW. The results of SRW and/or SRDW are understood to be not only particular documents (report, article, patent, etc.), but also methods, technologies, algorithms, etc. developed by magistrand. The resources for realization of the process are: intellectual capital of research institute and its manufacturing base.

Block A12. Doing scientific-and-research practices. The process possesses the goals similar to A11 process: the formation of magistrands' competences linked to SRW and/or SRDW. The difference is that scientific-and-research practice is provided by curriculum and as opposed to collateral execution of SRW and/or SRDW is being obligatory training mode.

Block A13. Attraction of personnel of research institutes to teaching process. The aim of the present process is the attraction on a contract basis of personnel of research institutes to magistrands' training. It was made to equip magistrands with relevant data about state of fundamental and applied science in chosen training direction. 


\subsubsection{A2 diagram for the process of engineering and scientific-and-technical staff formation in the course of training in postgraduate school. Process: "Specialized companies integration"}

In figure 8 there is A2 diagram that shows the content of A2 process - "specialized companies integration".

Block A21. Participation in manufacturing activity of specialized company. The present process is aimed at formation of magistrands' competences linked to manufacturing activity of specialized companies. The input of the process is the magistrands, the output is the magistrands acquired the necessary competences, and also the results of magistrand's participation in manufacturing activity of specialized partner company. The resources for realization of the process are the intellectual capital of specialized company and its manufacturing base.

Block A22. Collateral execution of SRW and SRDW in specialized companies. Speaking about companies working in science-intensive branches of economy, we can consider another one form of cooperation between higher education institution and a company: the attraction of magistrands to participation in SRW and/or SRDW of the company. The resources of the process are also represented with knowledge and experience of company's personnel and materiel and technical support for execution of SRW and/or SRDW.

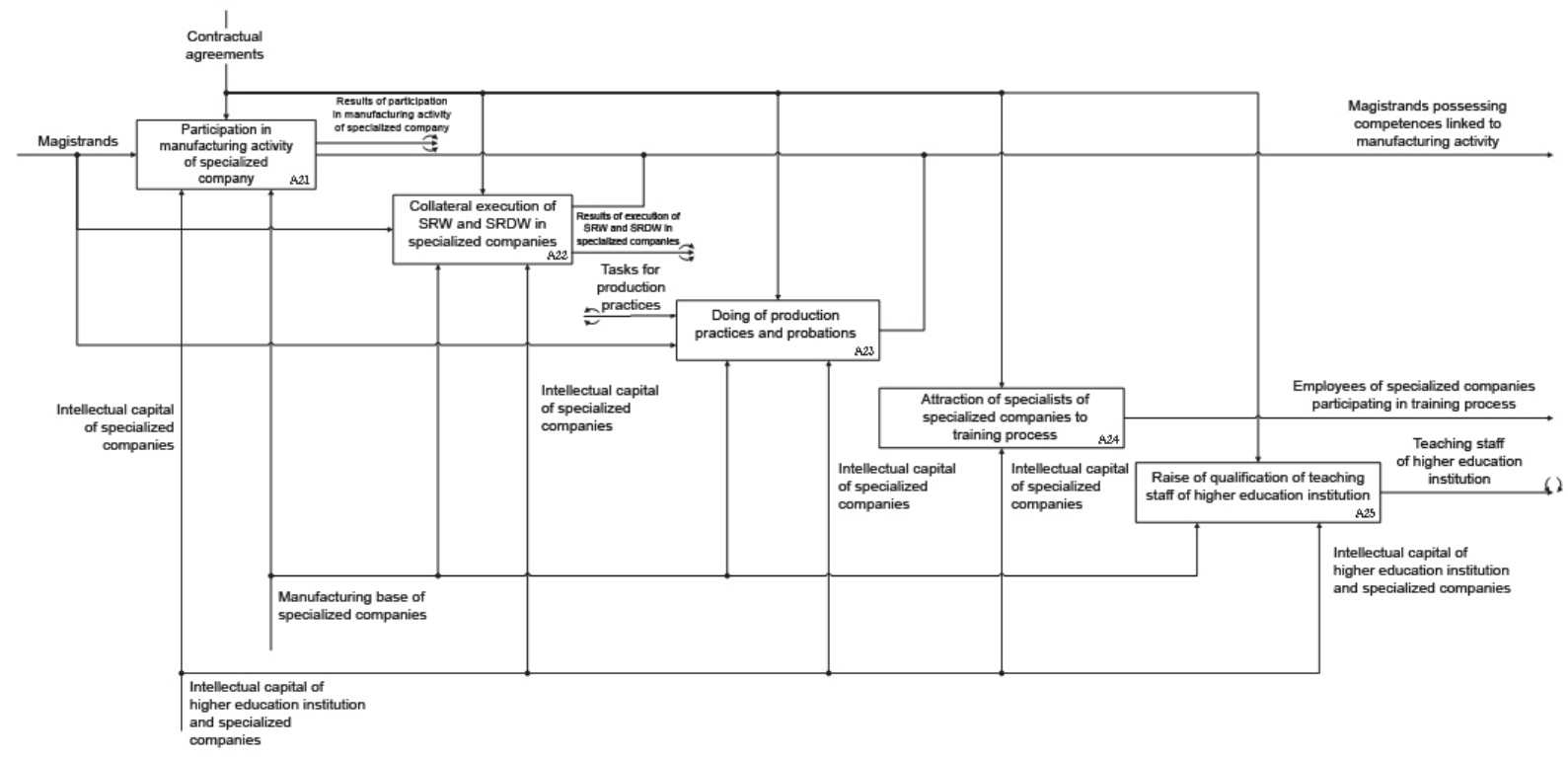

Figure 8. A2 diagram for the process of engineering and scientific-and-technical staff formation in the course of training in postgraduate school. Process: "Specialized companies integration"

Block A23. Doing production practices and probations. The full analogy with A12 process. The production practice is provided by curriculum and is being, as opposed to A21 and A22 processes, obligatory training mode. Doing production practice in specialized company a magistrand also acquires competences linked to its manufacturing activity.

Block A24. Attraction of specialists of specialized companies to teaching process. The process is aimed at attraction of specialized companies' specialists to teaching process. The participation of such specialists in magistrands' training provides synchronization of teaching material with current requirements of companies to employee's competences. The present circumstance grades the break between "the things that are sold" and "the things that are being necessary for business".

Block A25. Raising of qualification of teaching staff of higher education institution. Another one form of cooperation between higher education institution and specialized company can be raising of qualification of teaching staff. Such a cooperation form helps higher education institution to save funds on attraction of highly-skilled professionals for training of magistrands. The employees of specialized company teach academics, who transfer the knowledge to magistrands. The output of the present process is the teachers of higher education institution possessing relevant knowledge and competences. The resources for project's realization are: intellectual capitals of higher education institution (the representatives of higher education institution) and specialized company (highly-skilled professionals of partner company). 
3.2.5 A3 diagram for the process of engineering and scientific-and-technical staff formation in the course of training in postgraduate school. Process: "Creation of interdepartmental complexes for realization of cross-disciplinary projects"

In figure 9 there is A3 diagram that shows the content of A3 process - "The creation of interdepartmental complexes for realization of cross-disciplinary projects".

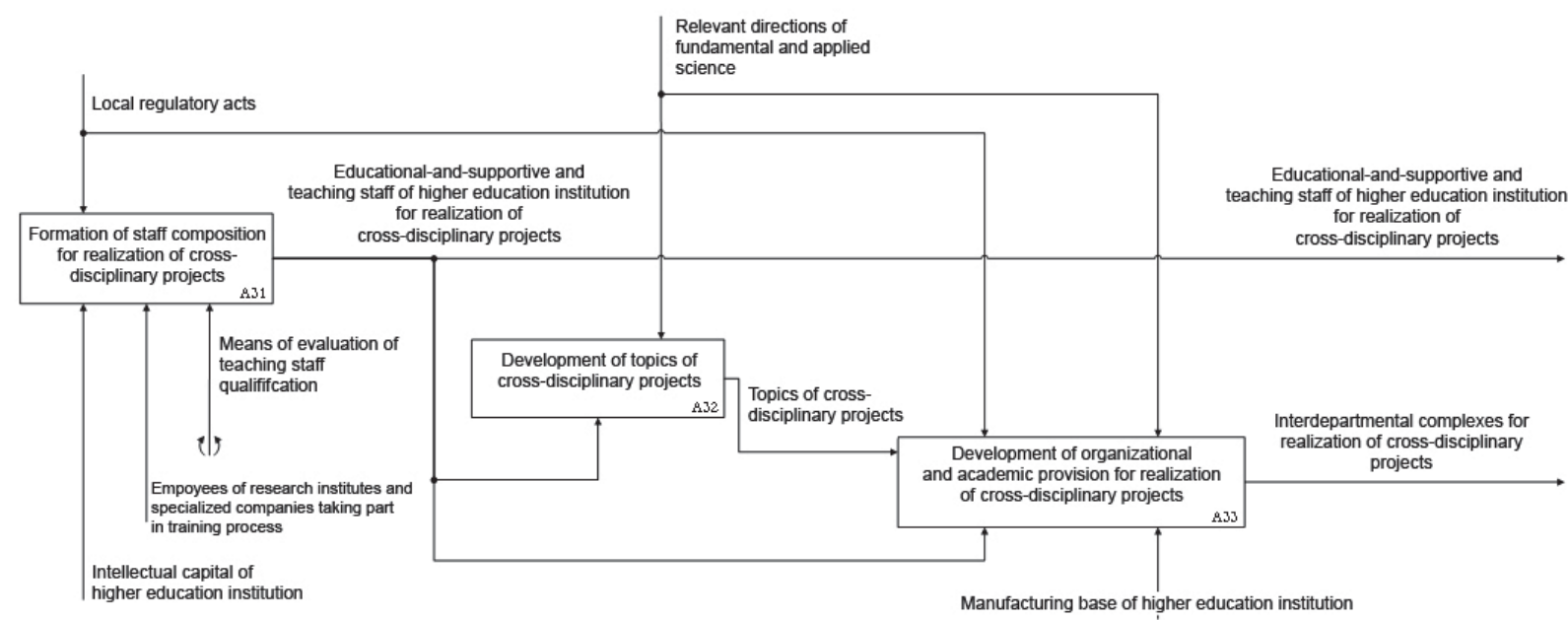

Figure 9. A3 diagram for the process of engineering and scientific-and-technical staff formation in the course of training in postgraduate school. Process: "Creation of interdepartmental complexes for realization of cross-disciplinary projects"

Block A31. Formation of staff composition for realization of cross-disciplinary projects. The aim of this process is the creation of teams for realization of cross-disciplinary projects from amongst teacher of higher education institution, and also employees of partner research institutes and specialized companies attracted to teaching process. Here we should specify that execution of project is the magistrand's task, while selected teachers can just render consultation services. The resources of the present project are: human capital of higher education institution, personnel of research institute and specialized companies taking part in training process, and also - the means of evaluation of teaching staff qualification. The means of teaching staff qualification's evaluation are necessary for assigning consultants for cross-disciplinary projects, who possess knowledge and skills necessary for the process. In figure 10 there is a team of cross-disciplinary project taken all round (Akhterov A.V. and Minina O.G., 2013).

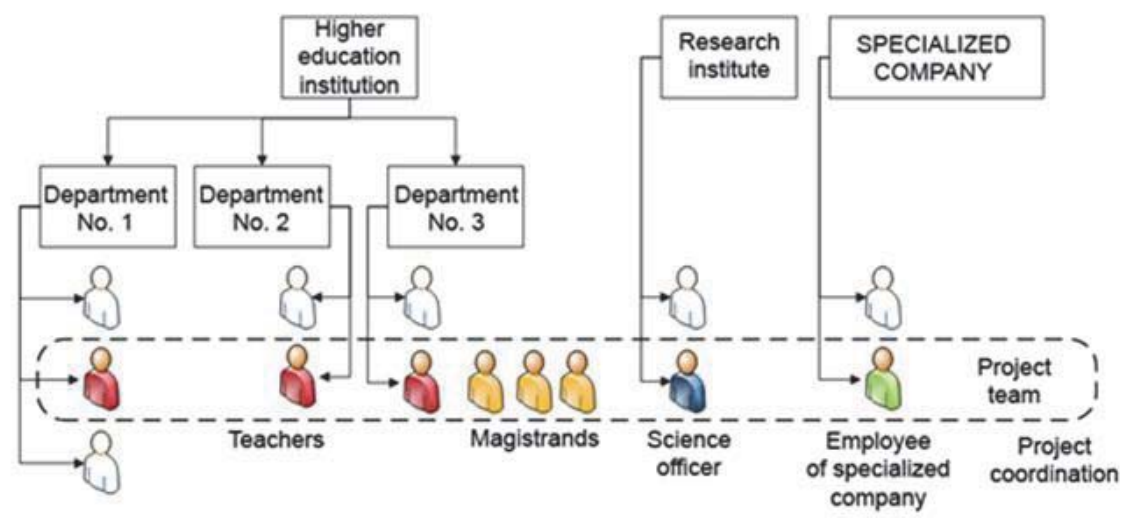

Figure 10. Composition of cross-disciplinary project's team

Block A32. Development of topics for cross-disciplinary projects. The process is aimed at the development of topics for 
future cross-disciplinary projects. The development is dealt by the teachers selected in A31 process.

Block A33. Development of organizational and academic provision for cross-disciplinary projects' realization. The process is aimed at the creation of interdepartmental educational complexes including topics of future cross-disciplinary projects, and also academic, regulatory and organizational provision for their execution. All the types of provision are developed by educational-and- educational supportive and teaching staff of higher education institution selected in A31 process.

3.2.6 A4 diagram for the process of engineering and scientific-and-technical staff formation in the course of training in postgraduate school. Process: "Execution of cross-disciplinary projects and making of master's thesis".

In figure 11 there is A4 diagram that shows the content of A4 process - "The execution of cross-disciplinary projects and making of master's thesis".

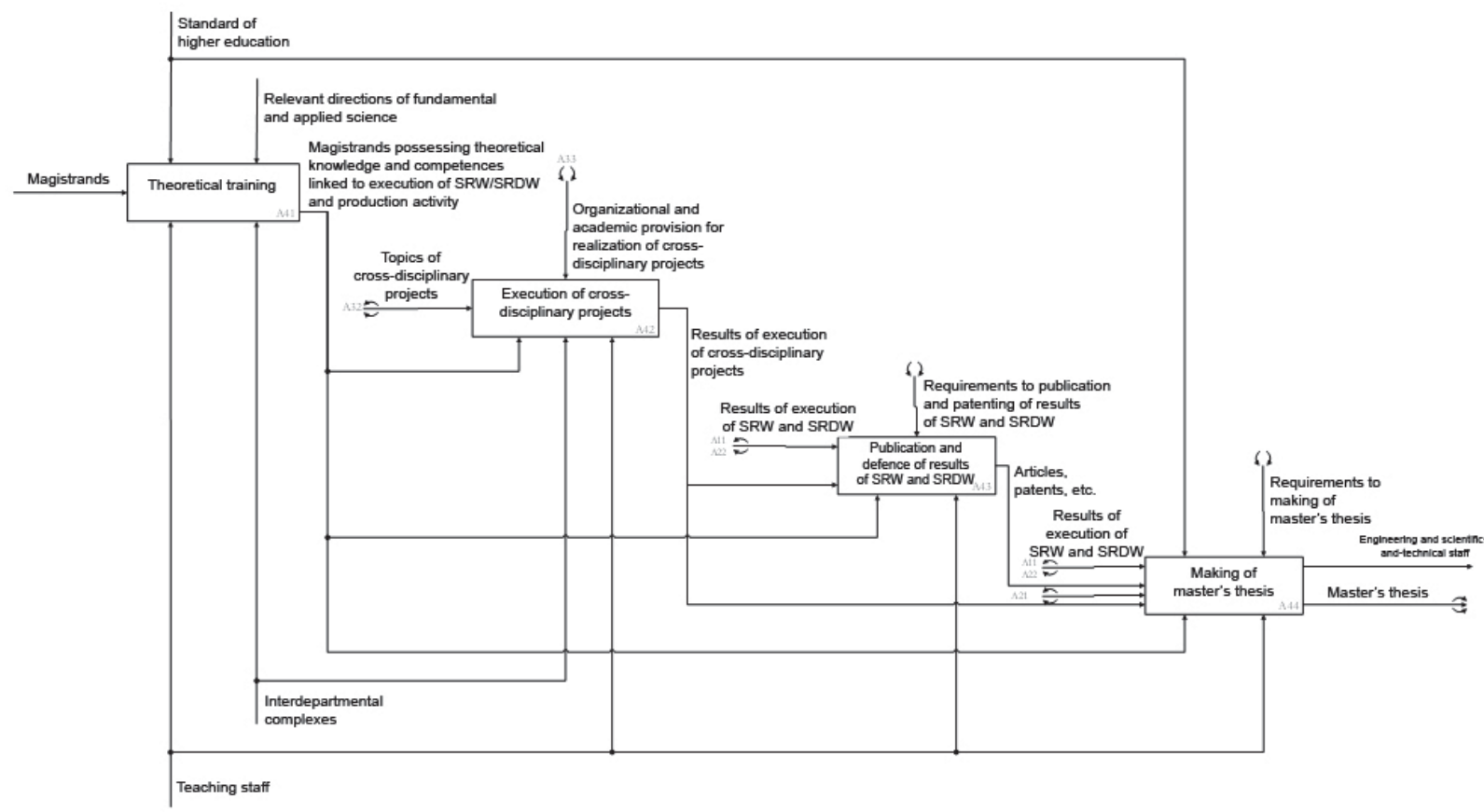

Figure 11. A4 diagram for the process of engineering and scientific-and-technical staff formation in the course of training in postgraduate school. Process: "Execution of cross-disciplinary projects and making of master's thesis"

Block 41. Theoretic training. The process implies the formation of theoretical basis necessary for execution of crossdisciplinary project by magistrands. Despite the fact that the output of this process is the magistrands possessing theoretical knowledge and all the necessary competences, this does not mean the theoretical knowledge are given after practice in research institute and specialized companies. The matter is that the IDEF0 diagrams in a general way do not show the time sequence of execution of processes. Thus, A4 process (see figure 5) not necessarily starts after execution of $A 1, A 2$ and $A 3$ processes. All these four processes can pass simultaneously. Since theoretical knowledge is necessary for execution of cross-disciplinary projects, one of the resources of the present process is the interdepartmental complexes developed in A3 process. The second resource is the teachers selected in the process of formation of staff composition for cross-disciplinary projects' realization.

Block 42. Execution of cross-disciplinary projects. If A33 process was aimed at the formation of all the types of provision for execution of cross-disciplinary projects, the present process represents the execution of these projects by magistrands. The input for the process is the topics of cross-disciplinary projects developed in A32 process.

Block 43. Publication and the defence of results of SRW and SRDW. The necessary component of training in postgraduate school is the publication of results of scientific-and-research activity.

Block 44. Making of master's thesis. The final stage of training in postgraduate school is the making of master's 
thesis. The input of the present process is all the earlier obtained results that are: the results of SRW and SRDW obtained in branch research institute, the results of magistrand's participation in manufacturing activity of specialized company. The result of the process is the engineering and scientific-and-technical staff in general represented with magistrand possessing the competences linked as to participation in SRW and SRDW, so to participation in manufacturing activity of specialized company, and ready for realization of cross-disciplinary projects as well.

\section{Discussion}

According to the results of analysis of objective factors that influence social development of technical intelligentsia, we can make an overall conclusion that modern social-and-economic and political situation in the country does not promote its qualitative renewal and the social role, which can be and must be played by technical intelligentsia in the development of society.

One of the main stages of formation of engineering and scientific-and-technical staff, in authors' opinion, is the training in graduate school. Namely the training in graduate school provides full integration of competences linked to scientific inquiry and conduction of developmental works and competences linked to specialized manufacturing activity into the future of a specialist.

As a result of SADT-modeling four general processes of formation of engineering and scientific-and-technical staff were distinguished: cooperation with branch research institutes, integration to specialized companies, creation of interdepartmental complexes for realization of cross-disciplinary projects, execution of cross-disciplinary projects and making of master's thesis. The decomposing of each of above-listed processes was carried out.

We should also pay attention to some disadvantage of offered approach and probable direction of future researches. SADT-modeling implies multiple execution of author/reader cycle for specification of all the diagram's details. Despite the fact the models represented in the work had been verified and criticized in professional environment, the process of specification of different details of diagrams (correctness of decomposing, as well as correct identification of arcs of inputs, outputs, control and mechanisms) can not be considered completed. The future studies can be preceded in two directions: "widthwise modeling" and "in-depth modeling". The first case implies modeling of other forms of higher education (bachelor's programme, postgraduate education, etc.) (see figure 3), the second case implies conduction of further decomposing of processes represented in the work and also the concretization of some methods and instruments being part of the models. Some steps in this regard are already taken, particularly, in (Shastina, Vrazhnova) the matter of formation of engineering and scientific-and-technical staff's administrative competences (the first direction of studies), while in (Akhterov and Lezina, 2013) there is an approach to designing of informational and educational component of pedagogic system for knowledge management at producing department of higher education institution (the second direction of studies).

\section{Acknowledgement}

The paper was made in the frameworks of execution of project part of national task in 2015 (project No. 28.2049.2014/K).

\section{References}

Akhterov, A. V., \& Lezina, O. V. (2013). Designing of the information component of pedagogical knowledge management system in a chair of technical university. Interactive Collaborative Learning (ICL), 2013 International Conference on, pp. 544 - 546. http://dx.doi.org/ 10.1109/ICL.2013.6644647

Akhterov, A. V., \& Minina, O. G. (2013). The synergetic approach to the substantiation of introduction of project-oriented management at the University. Interactive Collaborative Learning (ICL), 2013 International Conference on, pp. 396 - 397. http://dx.doi.org/10. 1109/ICL.2013.6644608

Dynkin, A. A., \& Baranovsky, V.G. (2014). Russia and the world: 2015. Economy and external policy. Annual forecast. Moscow: The institute of world economy and foreign relations of the Russian Academy of Sciences.

Federal State Statistics Service. (2014). Social standing and social standard of living in Russia. Retrieved from: http://www.gks.ru/bgd/ regl/b14_44/Main.htm (February 17, 2015)

Gaponenko, A. L., \& Orlova, T. M. (2008). Knowledge management. How to turn knowledge into capital. Moscow: Eksmo

Integration definition for function modeling (IDEF0) (1993). Draft Federal Information Processing Standards Publication 183. Retrieved from: http://www.idef.com/pdf/idef0.pdf (February 17, 2015)

Makarenko, E. I. (2013). Different approaches to the concept of "technical intelligentsia" in Russian and West sociology. Interactive Collaborative Learning (ICL), 2013 International Conference on, pp. 369 - 370. http://dx.doi.org/10.1109/ICL.2013.6644601 
Primakov, E. M. (2011). Thoughts aloud. Moscow: Rossiyskaya gazeta.

Rossiyskays gazeta (2012, October 13). Pure motives.

Rutkevich, M. N. (2004). Social structure. Moscow: Alfa.

Shastina, A. E. \& Vrazhnova, M. N. (2013). Development needs of engineers relating to organizational and managerial competencies. Interactive Collaborative Learning (ICL), 2013 International Conference on, pp. 348 - 350. http://dx.doi.org/10.1109/ ICL.2013.6644595.

Stewart, T.A. (1997). Intellectual Capital. The New Wealth of Organizations. N.Y.-L., Doubleday

Vasilyev, V. N., \& Gurtov, V. A. (2008). Labour and educational services market in constituents of the Russian Federation. Moscow: Tehnosfera. 
ISSN 2039-2117 (online) ISSN 2039-9340 (print)
Mediterranean Journal of Social Sciences MCSER Publishing, Rome-Italy
Vol 6 No $3 \mathrm{~S} 3$ May 2015 